\title{
Magnetic field guided formation of long carbon filaments (sausages)
}

\author{
Vilas G. Pol ${ }^{\text {a }}$, Swati V. Pol ${ }^{\text {a }}$, Aharon Gedanken ${ }^{\mathrm{a}, *}$ Mun-Gyu Sung ${ }^{\mathrm{b}}$, Shigeo Asai ${ }^{\mathrm{b}}$ \\ a Department of Chemistry, Bar-Ilan University, Ramat-Gan 52900, Israel \\ b Department of Materials Processing Engineering, Graduate School of Engineering, Nagoya University, \\ Furo-cho, Chikusa-ku, Nagoya 464-8603, Japan \\ Received 18 March 2004; accepted 13 May 2004 \\ Available online 20 July 2004
}

Keywords: A. Carbon filaments; B. Heat treatment; C. Scanning electron microscopy

Carbon scientists throughout the world have been attracted to the study of the structure, texture and diversity of various carbon materials due to their wide range of application in nanodevices [1], energy storage [2], separation technologies [3] and lubricants. By very different processes, carbon nanotubes, spheres, beads, onions, glassy carbon, and pyrolytic carbon have been synthesized. All carbon materials formed from different precursors when heated to about $1300-1500{ }^{\circ} \mathrm{C}$ under reduced pressures form hexagonal layers of carbon atoms [4]. Each carbon material has a different way of aggregating upon cooling of these hexagonal layers, which leads to the formation of various textures. Recently, magnetic field-induced growth and self-assembly of cobalt nanocrystallites was studied by Niu et al. [5]. Other reports in which a chemical reaction was conducted in a magnetic field include the order observed in assemblies of superparamagnetic carrier particles reported by Rotariu [6], strain detected in iron-based ferromagnetic shape memory alloys reported by Sakamoto et al. [7] and superconductivity measured in hybrid ferromagnets [8].

In our recent publication we have discussed the synthesis of carbon spherules, its properties and the mechanism of its formation [9]. To the best of our knowledge there are no direct reports of the effect of applying a magnetic field on the synthesis of pure carbon bodies. This article shows how the magnetic field affects a reaction, which without the magnetic field leads to the formation of uniform, mono-dispersed, high purity carbon spherules (CSs) without using a catalyst. The reaction, which is the subject of this paper, is the dissociation of mesitylene at $700{ }^{\circ} \mathrm{C}$. This reaction was studied with and without a magnetic field. Without a magnetic field it yields $2.5 \mu \mathrm{m}$ spherical carbon bodies with a very narrow size distribution. When the same reaction is conducted under an applied magnetic field, it leads to the formation of long carbon filaments (CFs). It \footnotetext{
51250 .

Corresponding author. Tel.: +972-353-18315; fax: +972-353-

E-mail address: gedanken@mail.biu.ac.il (A. Gedanken).
}

is interesting to note that the dissociation of mesitylene always leads to a product with exactly the same dimensions. It is impossible to change the shape and diameter of the CSs under a wide range of reaction conditions. Different temperatures, various amounts of precursor, different surrounding atmospheres, and various heating times always yield CSs of $2.5 \mu \mathrm{m}$. Only after applying a high magnetic field of $10 \mathrm{~T}$ to the reaction cell did we get a different-shape product. We have obtained long CFs whose length varies between 10 and $32 \mu \mathrm{m}$. Very recently [10] we have demonstrated the effect of a magnetic field on a RAPET (reaction under autogenic pressure at elevated temperature) of $\mathrm{MoO}(\mathrm{OMe})_{4}$; fabrication of $\mathrm{MoO}_{2}$ nanoparticles coated with carbon or separated $\mathrm{MoO}_{2}$ and carbon particles. The products of the reactions with and without a magnetic field were characterized by CHNS analysis, elemental analysis, SEM and ESR techniques. Table 1 we presents the various reaction parameters under which the reaction was conducted and the morphologies of the products.

The synthesis of CSs and CFs was carried out by introducing mesitylene [97\%, 1,3,5-trimethyl benzene $\left(\mathrm{C}_{6} \mathrm{H}_{3}\right)\left(\mathrm{CH}_{3}\right)_{3}$, bp $=162-164^{\circ}$, Aldrich Chem. Com.] into a $4 \mathrm{ml}$ closed cell. The cell is assembled from stainless steel swagelok parts. A $\frac{1}{2}$ in. union part is capped from both sides by standard plugs. For this synthesis, $1.5 \mathrm{ml}$ of mesitylene is introduced into the cell at room temperature under air. The filled swagelok is closed tightly by the other plugs and then placed for heating at $700{ }^{\circ} \mathrm{C}$ for $3 \mathrm{~h}$. The temperature is raised at a heating rate of $5^{\circ} \mathrm{C}$ per minute. The reaction took place at an autogenic pressure of the precursor. The swagelok is gradually cooled $(\sim 5 \mathrm{~h})$ to room temperature, opened, and $1.15 \mathrm{~g}$ dark black powder is collected. The yield of the product is $85 \%$ according to carbon $\mathrm{wt} \%$ and $77 \%$ according to mesitylene $\left(\mathrm{C}_{9} \mathrm{H}_{12}\right)$. The rest of the probable weight loss is due to the formation of byproducts such as methane, water, and carbon oxides.

The same procedure was carried out under a static magnetic field of $10 \mathrm{~T}$, which was generated using a helium free superconducting magnet. The swagelok was set in the maximum magnetic point in the bore of the 
Table 1

Reaction conditions for the synthesis of carbon spherules and filaments

\begin{tabular}{|c|c|c|c|c|}
\hline Sample no. & Precursor & Temp./time & Atmosphere inside cell & Morphology/TEM and size \\
\hline 1 & Mesitylene & $700^{\circ} \mathrm{C} / 3 \mathrm{~h}$ & Air & $\mathrm{CSs}$ \\
\hline 2 & Mesitylene & $700{ }^{\circ} \mathrm{C} / 24 \mathrm{~h}$ & Air & CSs \\
\hline 3 & Mesitylene & $700{ }^{\circ} \mathrm{C} / 3 \mathrm{~h}$ & Argon & $\mathrm{CSs}$ \\
\hline 4 & Mesitylene & $900^{\circ} \mathrm{C} / 3 \mathrm{~h}$ & Air & CSs \\
\hline 5 & Mesitylene* & $700^{\circ} \mathrm{C} / 3 \mathrm{~h}$ & Air & $\mathrm{CSs}$ \\
\hline 6 & Mesitylene $^{* *}$ & $700^{\circ} \mathrm{C}$ & Air & CSs \\
\hline 7 & Mesitylene $^{* * *}$ & $700^{\circ} \mathrm{C} / 3 \mathrm{~h}$ & Air & CSs \\
\hline 8 & Mesitylene ${ }^{* * * *}$ & $700^{\circ} \mathrm{C} / 3 \mathrm{~h}$ & Air & CFs \\
\hline
\end{tabular}

${ }^{*}$ After heating a swagelok at $700{ }^{\circ} \mathrm{C} / 3 \mathrm{~h}$, a very slow cooling rate, $1{ }^{\circ} \mathrm{C} / \mathrm{min}$.

** Very slow heating rate $1{ }^{\circ} \mathrm{C} / \mathrm{min}$.

*** The swagelok is filled with mesitylene $(>80 \%)$.

${ }^{* * * *}$ Heating a swagelok at $700{ }^{\circ} \mathrm{C} / 3 \mathrm{~h}$ under a magnetic field of 10 Tesla.

magnet, where the gradient of the magnetic field was the smallest. A ceramic oven containing the swagelok filled with $1.5 \mathrm{ml}$ of mesitylene was placed between the magnetic poles. The oven was heated and cooled as in the reaction without magnetic field. The yield of the product is $76 \%$. Scanning electron microscope images were obtained using JEOL 6300F. EPR spectrum was recorded on a Bruker EPR spectrometer (ER083 CS) operating at $\mathrm{X}$-band $(v=9.77 \mathrm{GHz})$, with a $100 \mathrm{kHz}$ magnetic field modulation.

The elemental composition of the CSs and CFs was measured by energy-dispersive X-ray analysis. In all the as-prepared samples of CSs and CFs, only carbon is observed, and no evidence is found for any other impurity. The $\mathrm{C}, \mathrm{H}, \mathrm{N}, \mathrm{S}$ analysis shows the presence of carbon $(>99 \%)$ and a very small presence of hydrogen $(<0.7 \%)$ in CSs and CFs. The same pyrolytic, non-graphitic X-ray diffraction pattern [9] is observed for the CFs as the CSs.

The SEM images of the products obtained in the 700 ${ }^{\circ} \mathrm{C}$ decomposition of mesitylene with and without a magnetic field are presented in Fig. 1. The representative SEM image (Fig. 1a) shows the spherical morphology of the CSs, with an average diameter of $2.5 \mu \mathrm{m}$. Similar pictures were obtained in TEM measurements but they are not presented here. A perfect spherical shape and
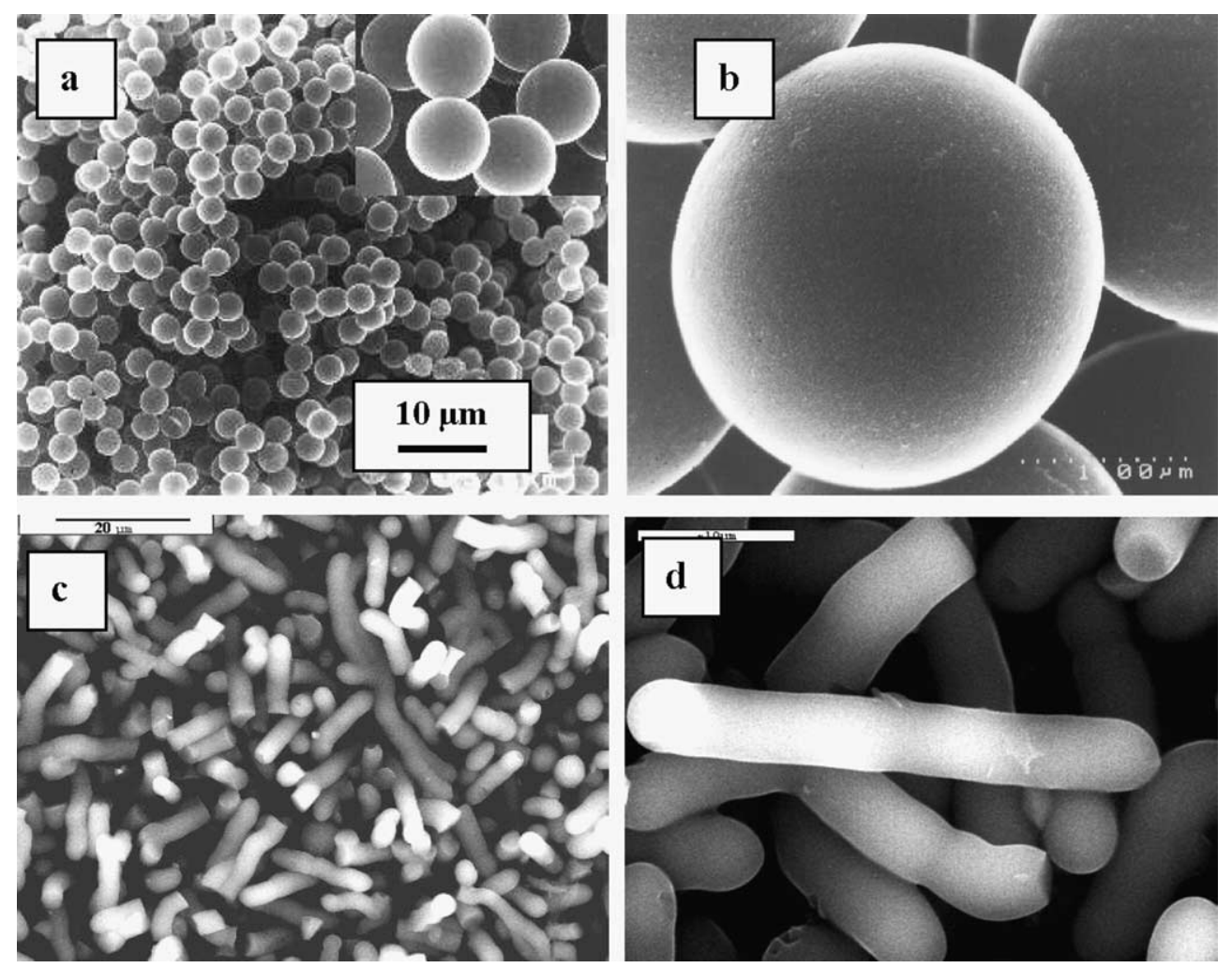

Fig. 1. SEM images of the (a) CSs and (b) CS shown at high resolution, and (c) CFs synthesized under a magnetic field and (d) CF shown at high resolution. 
smooth surface can be seen at the HR-SEM picture (Fig. 1b). The as-prepared CSs are solid and not hollow, confirmed by TEM image of the horizontal cross-section of a CS. Identical carbon spherules were obtained under various reaction conditions such as different temperatures, various amounts of precursors, different surrounding atmospheres, and various heating times (Table 1).

The SEM image of the as-prepared carbon filaments under a magnetic field (Fig. 1c) shows the sausage diameter in the range of $2-4 \mu \mathrm{m}$, and lengths varying in the range of $10-32 \mu \mathrm{m}$. In addition to filaments, CSs (average diameter $2.5 \mu \mathrm{m}$ ) are also observed. Fig. 1c shows that more than $90 \%$ of the carbon bodies are converted into filaments under a magnetic field and only $10 \%$ are still $2.5 \mu \mathrm{m}$ carbon spherules. A perfect sausage shape and smooth surface can be seen at the HR-SEM picture (Fig. 1d).

Fig. 2a shows the transmission electron micrograph of the carbon filaments synthesized under a magnetic field of $10 \mathrm{~T}$. The diameter of $\sim 2.5 \mu \mathrm{m}$ and the length up to $20-25 \mu \mathrm{m}$ is observed. The TEM of an individual CF (Fig. 2b) shown at high resolution presents a perfect sausage shape and smooth surface with the diameter of $-2.5 \mu \mathrm{m}$ and length of $12 \mu \mathrm{m}$. The nature of the CFs is a solid and not a hollow, confirmed by TEM image of the horizontal cross-section of the CF. The sizes/shapes of the CFs observed by SEM measurements matches with the TEM measurements.

The elemental composition of the CFs and CSs are analyzed by energy-dispersive X-ray analysis. In both the as-prepared samples of CFs and CSs, only carbon is observed, and no evidence is found for any other impurity (Fig. 3).

Electron paramagnetic resonance (EPR) spectra of the CSs and CFs samples taken at room temperature are the same and are shown in Fig. 4. The $g$-factor is a

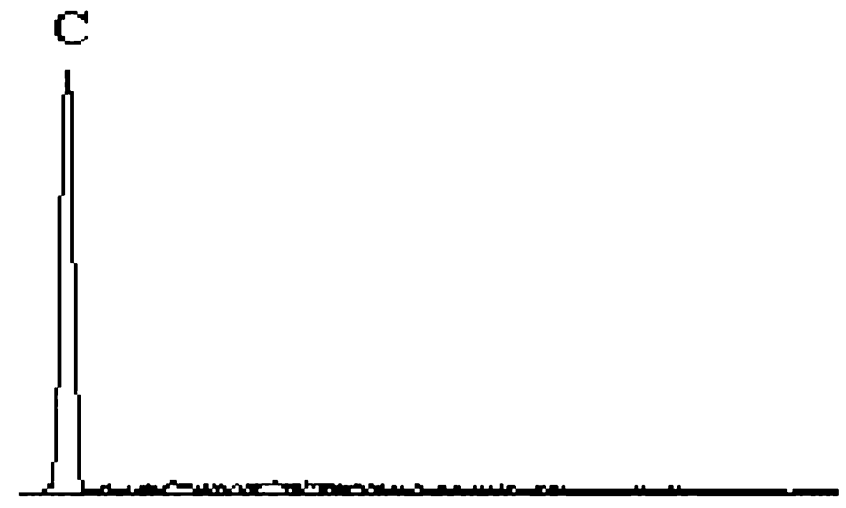

Fig. 3. EDAX spectrum of the CFs/CSs.

dimensionless constant and is equal to 2.002319 for an unbound electron [11]. The CSs sample showed a peakto-peak separation $\left(\Delta H_{\mathrm{pp}}\right)$ of $40 \mathrm{G}$ and a g-value of 2.00277. This narrow paramagnetic resonance signal (width $40 \mathrm{G}$ ) matches well with the carbon black reported by Mrozowski [12]. He found that the width of the ESR line is inversely proportional to the concentration of the grafted radical groups. Mrozowski has published a series of comprehensive studies on the ESR of carbonaceous moieties. One of his main conclusions

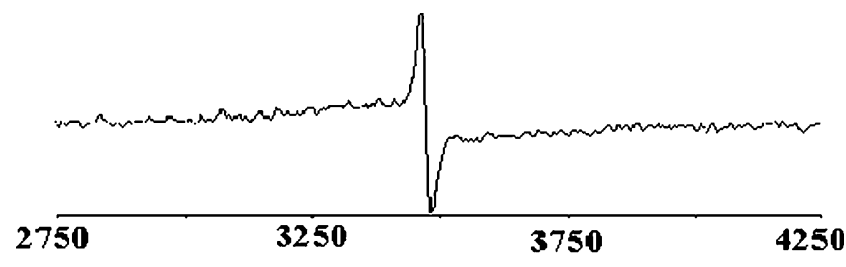

[G]

Fig. 4. Electron paramagnetic resonance exhibited at room temperature by CSs and CFs.
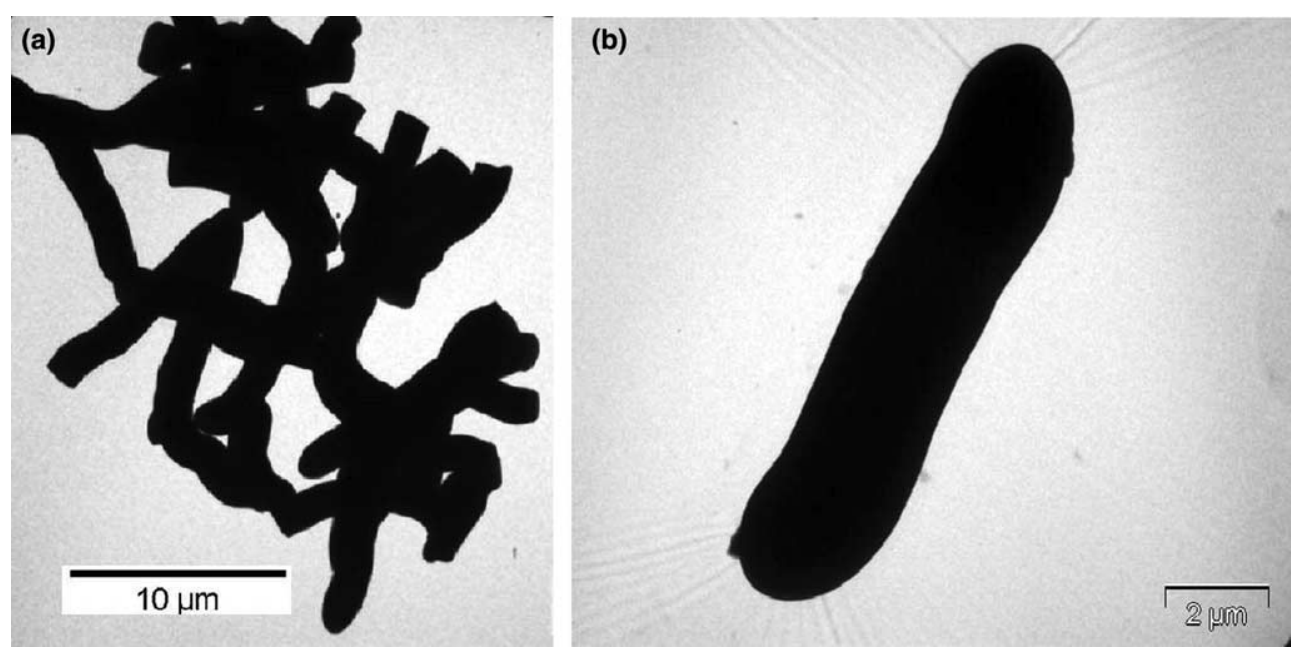

Fig. 2. TEM images of the Carbon filaments (a) synthesized under a magnetic field and (b) CF shown at high resolution. 
was that all carbonaceous substances at some stage of transformation into carbons go through a phase involving formation of stable radicals [13]. The magnetic field induces the interaction between these stable radicals and causes the growth of the carbon body to dimensions of $32 \mu \mathrm{m}$. It also affects the longitudinal direction of the growth reflected in the formation of a long sausage. Upon the dissociation of mesitylene at 700 ${ }^{\circ} \mathrm{C}$, and during the three hours of heating, a spherical embryo of carbon is formed. The magnetic field directs the interaction between these small spheres, leading to the formation of the carbon filaments. It is intricate to determine whether the CFs are growing along the field direction, since after the opening of the swagelok the product is getting mixed.

\section{Acknowledgements}

V.G. Pol is grateful to Bar-Ilan University, Israel, for financial assistance.

\section{References}

[1] Collins PG, Zettl A, Bando H, Thess A, Smalley RE. Nanotube nanodevice. Science 1997;278(5335):100-3.

[2] Che GL, Lakshmi BB, Fisher ER, Martin CR. Carbon nanotubule membranes for electrochemical energy storage and production. Nature 1998;393(6683):346-9.
[3] Shiflett MB, Foley HC. Ultrasonic deposition of high-selectivity nanoporous carbon membranes. Science 1999;285(5435): 1902-5.

[4] Inagaki M. Carbon materials - structure, texture and intercalation. Solid State Ionics 1996;86-88:833-9.

[5] Niu HL, Chen QW, Zhu HF, Lin YS, Zhang X. Magnetic fieldinduced growth and self-assembly of cobalt nanocrystallites. J Mater Chem 2003;13(7):1803-5.

[6] Rotariu O, Strachan NJC. Magnetic-field-induced order in assemblies of superparamagnetic carrier particles. Powder Technol 2003;132(2-3):226-32.

[7] Sakamoto T, Fukuda T, Kakeshita T, Takeuchi T, Kishio K. Magnetic field-induced strain in iron-based ferromagnetic shape memory alloys. J Appl Phys 2003;93(10):8647-9.

[8] Lange M, Van Bael MJ, Bruynseraede Y, Moshchalkov VV. Nanoengineered magnetic-field-induced superconductivity. Phys Rev Lett 2003;90(19), Art. No. 197006.

[9] Pol VG, Motiei M, Gedanken A, Calderon-Moreno J, Yoshimura M. Carbon spherules: synthesis, properties and mechanistic elucidation. Carbon 2004;42(1):111-6.

[10] Pol SV, Pol VG, Kessler VG, Seisenbaeva GA, Sung M, Asai S, et al. The effect of a magnetic field on a RAPET (reaction under autogenic pressure at elevated temperature) of $\mathrm{MoO}(\mathrm{OMe})_{4}$; fabrication of $\mathrm{MoO}_{2}$ nanoparticles coated with carbon or separated $\mathrm{MoO}_{2}$ and carbon particles. J Phys Chem B 2004;108: 6322-7.

[11] Willard, Merrit, Dean. Instrumental methods of analysis. 5th ed. 1974. p. 236.

[12] Mrozowski S. ESR of carbons in the transition range 1. Carbon 1979;17(3):227-36.

[13] Mrozowski S. Carbon, electron-spin-resonance studies of carbonization and coalification processes. 1. Carbonaceous compounds. Carbon 1988;26(4):521-9.

\title{
The cutting of MWNTs using gamma radiation in the presence of dilute sulfuric acid
}

\author{
Jing Peng ${ }^{\mathrm{a}}$, Xiaoxing $\mathrm{Qu}{ }^{\mathrm{a}}$, Genshuan Wei ${ }^{\mathrm{a}, *}$, Jiuqiang $\mathrm{Li}^{\mathrm{a}}{ }^{\text {, Jinliang Qiao }}{ }^{\mathrm{b}}$ \\ ${ }^{a}$ Institute of Applied Chemistry, College of Chemistry, Peking University, Beijing 100871, China \\ ${ }^{\mathrm{b}}$ SINOPEC Beijing Research Institute of Chemical Industry, Beijing 100013, China
}

Received 22 April 2004; accepted 13 May 2004

Available online 20 June 2004

Keywords: A. Carbon nanotubes; B. Chemical treatment; D. Chemical structure, Radiation damage

Carbon nanotubes (CNTs) are of great interest because of their novel structural, electronic and mechanical properties. Recently, CNTs with relatively short length in the range of $0.1-1 \mu \mathrm{m}$ have attracted much attention because they may provide connectors and components in molecular electronic devices such as

\footnotetext{
9191.

${ }^{*}$ Corresponding author. Tel.: +86-10-6275-7193; fax: +86-10-6275-

E-mail address: gswei@pku.edu.cn (G. Wei).
}

nano-tweezers and nano-bearings. However, CNTs are usually long and tangled which limits their applications. To obtain short CNTs, many methods have been developed, such as chemical etching [1], ultrasonic treatment [2] and scanning tunneling microscope (STM) voltage [3]. These techniques have a limited yield and often create structural damage. Short single-wall carbon nanotubes with average length $<50 \mathrm{~nm}$ could be produced by fluorination followed by pyrolysis up to 1000 ${ }^{\circ} \mathrm{C}[4]$, but the process is very complicated and energy 